\title{
Influence of Nanocrystalline Structure on Wear and Corrosion Behavior of $\mathrm{Al}-\mathrm{SiC}_{\mathrm{p}}$ Composite
}

\author{
Jagannati Venumurali*, Gaddam Bhanodaya Reddy \\ Department of Mechanical Engineering, College of Engineering, Sri Venkateswara University, Tirupati, India \\ Email: *murali.iskapalem502@gmail.com
}

\begin{abstract}
How to cite this paper: Venumurali, J. and Reddy, G.B. (2020) Influence of Nanocrystalline Structure on Wear and Corrosion Behavior of $\mathrm{Al}-\mathrm{SiC}_{\mathrm{p}}$ Composite. Journal of Minerals and Materials Characterization and Engineering, 8, 47-58.

https://doi.org/10.4236/jmmce.2020.82004
\end{abstract}

Received: March 3, 2020

Accepted: March 22, 2020

Published: March 25, 2020

Copyright $\odot 2020$ by author(s) and Scientific Research Publishing Inc. This work is licensed under the Creative Commons Attribution International License (CC BY 4.0).

http://creativecommons.org/licenses/by/4.0/

(c) (i) Open Access

\begin{abstract}
Functionally graded (FG) Al-SiC $\mathrm{P}_{\mathrm{P}}$ composites fabricated via centrifugal casting are widely used in automobile components particularly a brake rotor disc because of its high $\mathrm{SiC}$ fraction at the outer periphery. However, when operated in corrosive environment like road deicing salts the disc is highly sensitive to the corrosion due to high $\mathrm{SiC}$ fraction. But, the nanocrystalline (NC) structured surfaces synthesized by severe plastic deformation (SPD) method have excellent wear and corrosion resistance at the surface. Therefore, shot peening (SP) as a SPD method conducted on one side of the stir casted FG Al composite having $10 \mathrm{wt} \% \mathrm{SiC}_{\mathrm{P}}$ constant reinforcement in order to create $\mathrm{NC}$ structured surface. The SP treatment continued for $70 \mathrm{~s}$ and $140 \mathrm{~s}$ durations. Thereafter, the surface characteristics of the composite before and after SP were estimated by XRD and then the composites were tested by wear and corrosion tests. The results revealed that the SP for $140 \mathrm{~s}$ duration favors the induction of hardened layer, higher grain refinement (NC structure) and dislocation density which promotes the occurrence of high surface hardness, thus significantly improving its wear properties. However, higher dislocation density resulted from longer duration shown deterioration to the corrosion resistance. Whereas, the attained degree of NC structure is more pronounced over dislocation density resulted after $70 \mathrm{~s}$ SP duration, thereby composite showed excellent corrosion resistance. Thus, the composite with $70 \mathrm{~s}$ duration possessed excellent corrosion and relatively good wear properties too.
\end{abstract}

\section{Keywords}

Functionally Graded Al-SiC $\mathrm{P}_{\mathrm{P}}$ Composite, Shot Peening, NC Structure, Wear, Corrosion

\section{Introduction}

Aluminum metal matrix composites (AMMCs) offer superior benefits over an 
aluminum base matrix [1]. Because of their improved strength, stiffness and high wear resistance AMMCs are widely used in the structural [2] [3], automotive [4] [5] and marine applications [6]. As silicon carbide particles $\left(\mathrm{SiC}_{\mathrm{p}}\right)$ resides in the composites exhibit wear resistance and it increases as increasing $\mathrm{SiC}_{\mathrm{P}}$ fraction.

Therefore, brake rotor disc (BRD) of an automobile made by $\mathrm{Al}-\mathrm{SiC}_{\mathrm{P}} \mathrm{AMMC}$ needs to possess high wear resistance at the outer periphery and good toughness at the inner core. To satisfy this requirement, the BRD can be fabricated by centrifugal casting, then $\mathrm{BRD}$ will attain high $\mathrm{SiC}_{\mathrm{P}}$ fraction at outer periphery and decrease its fraction towards inner core by the centrifugal force [7]. But, when the $\mathrm{BRD}$ is in contact with road deicing salts, the presence of $\mathrm{SiC}_{\mathrm{P}}$ shows proneness to the corrosion by disrupting the formation of passive layer [8], and leads to the premature failure [9]. Moreover, corrosion intensity will increase with increase of $\mathrm{SiC}_{\mathrm{p}}$ fraction [8] and hence the $\mathrm{BRD}$ fabricated via centrifugal casting exhibiting high wear resistance but poor corrosion resistance.

To avert the corrosion proneness, a functionally graded (FG) A356-SiC $\mathrm{P}_{\mathrm{P}} \mathrm{BRD}$ composite fabricated via centrifugal casting and was heat treated with 1) solution annealing and 2) solution annealing + aging by Maimunnisa et al. [7]. After heat treatments, the samples were subjected to corrosion tests in $3.5 \mathrm{wt} \% \mathrm{NaCl}$ solution. After correlating the results with heat treatments, they have reported that the former treatment had shown the highest corrosion resistance than later treatment. Because aging of the solutionized composite by later treatment caused the formation of $\mathrm{Mg}_{2} \mathrm{Si}$ phase and weaken the corrosion resistance. Moreover, another article [10] declares that the heat treatments such as 1) solution treatment and 2) quenching + artificial aging have not affected the corrosion resistance of $\mathrm{FG} \mathrm{Al}-\mathrm{SiC}_{\mathrm{P}}$ composite fabricated via centrifugal casting.

From the above reports, it can conclude that the heat treatments are not

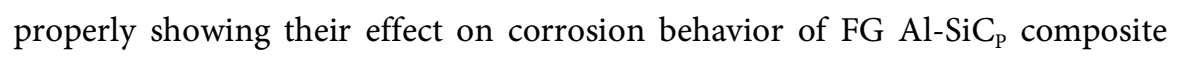
fabricated via centrifugal casting. Besides, the centrifugally cast $\mathrm{FG} \mathrm{Al-SiC}$ composite with high reinforcement fraction had also lost its wear resistance observed from water-lubricated pin-on-disc wear tests by Velhinho et al. [4]. Authors also explained that during wear tests in presence of water lubrication, the water acts as a carrier agent and transfers material from the pin samples. Also it pull-out $\mathrm{SiC}_{\mathrm{P}}$ from the region containing high $\mathrm{SiC}$ fraction. Water reacts at $\mathrm{Al}-\mathrm{SiC}$ interface particularly with $\mathrm{Al}$ matrix and provokes to the chemically induced fracture [11].

Recently, as wear and corrosion properties are being related to the material surface, surface NC structure developed by severe plastic deformation (SPD) was proposed to be convenient alternative to bypass these difficulties. The synthesized bulk NC component increases wear resistance [12], corrosion resistance [13], and harvesting superior benefits in material science [14].

Among the SPD techniques shot peening (SP) is a very familiar method and able to introduce NC layers with excellent features [15]. Properties by SP are far better when compared with heat treatments [16] and SP is widely used in indus- 
tries due to its flexibility to treat component of any shape, high productivity [15] and low cost [17] [18]. The AMMCs already yielded good results by SP but not studied wear and corrosion properties [19] [20].

Therefore, this work is aimed to study the wear and corrosion behavior of FG $\mathrm{Al}-\mathrm{SiC}_{\mathrm{P}}(10 \mathrm{wt} \%)$ composite by SP. In this regard, the effect of NC structure, dislocation density and exposure time by SP on microhardness, wear resistance, wear rate, friction coefficient, corrosion resistance and corrosion rate will be studied.

\section{Experimentation}

\subsection{Selection of Materials and Composite Fabrication}

The matrix alloy used in this work was Aluminum alloy 6061 as a substitute to aluminum alloy A356 [21], a constant weight fraction $10 \mathrm{wt} \% \mathrm{SiC}$ particles as reinforcement with size range from 40 to $55 \mu \mathrm{m}$ selected to fabricate the composite. The elemental composition of AA6061 matrix alloy was determined by optical emission spectroscopy and is presented in Table 1 . Then the composite after fabricating via stir casting turned into functionally graded metal matrix composite (FG AA6061-SiC $\mathrm{P}_{\mathrm{P}}$ ) [22]. After casting, the composite density was found to be $2.78 \mathrm{~g} / \mathrm{cm}^{3}$.

\subsection{Shot Peening (SP) and Surface Characterization}

The real setup and working schematic of SP are shown in Figure 1. The composite samples are treated by SP for 70 and $140 \mathrm{~s}$ exposure time on one side of the surface. Here, the un-shot peened specimens are referred to as un-SP, whereas shot peened specimens for $70 \mathrm{~s}$ and $140 \mathrm{~s}$ referred as SP70 and SP140 respectively. Then, SP involves the bombardment of the surface by small spherical shots.

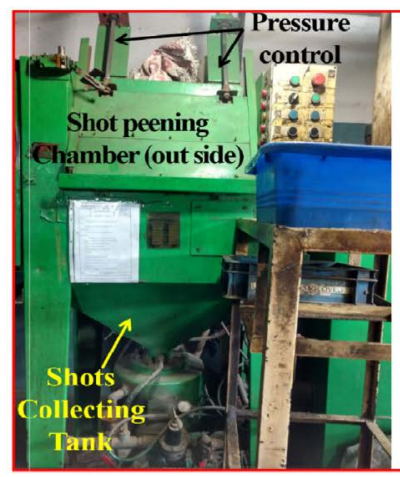

(a)

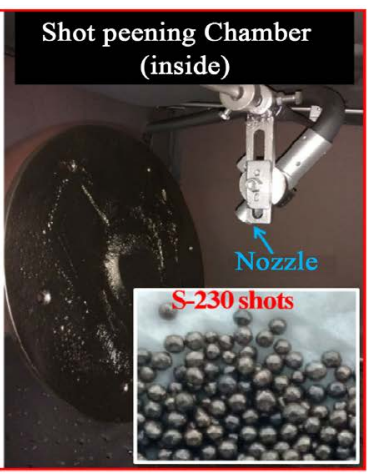

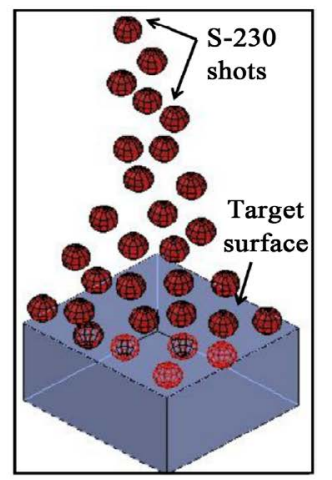

(b)

Figure 1. Shot peening (a) Real setup; (b) Operation schematic.

Table 1. The elemental composition of AA6061 aluminum alloy.

\begin{tabular}{cccccccccc}
\hline Element & $\mathrm{Cu}$ & $\mathrm{Mg}$ & $\mathrm{Zn}$ & $\mathrm{Mn}$ & $\mathrm{Si}$ & $\mathrm{Fe}$ & $\mathrm{Cr}$ & $\mathrm{Ti}$ & $\mathrm{Al}$ \\
\hline $\mathrm{Wt} \%$ & 0.33 & 1.24 & 0.41 & 0.39 & 0.78 & 0.31 & 0.3 & 0.24 & Balance \\
\hline
\end{tabular}


When the shots are coming out of the nozzle with high pressure energy, strikes over the target surface as shown in Figure 1 and this process usually takes place inside the SP chamber. The shot media used in this work are cast steel (S-230) according to standard SAE-AMS-2431/1 [23]. The diameter of shots used in this work ranging from 0.45 to $0.6 \mathrm{~mm}$ and having hardness 45 - $52 \mathrm{HRC}$ [24]. The other SP parameters selected in this work such as air pressure, nozzle distance, and impact angle are similar to the earlier work [25].

The phases formed on the surface of specimens were characterized using a Bruker D8 Advance X-ray Diffractometer with $\mathrm{Cu}-\mathrm{K} \alpha$ radiation and wave length of $1.54 \AA$. The phase and structure of the specimens were estimated by XRD profiles from $30^{\circ}$ to $80^{\circ}$ of $2 \theta$ variation. The phase analysis, full width at half maximum (FWHM), average grain size, dislocation density and lattice parameter were determined from this characterization.

\subsection{Experimental Procedure}

Microhardness was measured on both surface and cross-section of the specimens using a Vickers microhardness tester (Wilson Wolpert 401-MVD) as per the ASTM: E-92, under an applied load of 100 gf with dwelling time of $10 \mathrm{~s}$. The measurement was done for three times on each specimen and the average value was reported. For hardness profile from surface to interior at a series of planned points with $10 \mu \mathrm{m}$ interval followed and measured diagonally to overcome the effect of plastic deformation on the data reliability.

Dry sliding wear tests were conducted as per ASTM: G-99, in an ambient temperature using pin-on-disc apparatus using Ducom (TR20). The specimens were subjected to sliding under a load of $15 \mathrm{~N}$ against the rotating stainless steel (SS304) disc which had a hardness of 50 HRC. The disc was rotating with a linear velocity of $1.2 \mathrm{~m} / \mathrm{s}$ up to a sliding distance of $500 \mathrm{~m}$.

Corrosion tests were conducted on the specimens surface in $3.5 \mathrm{wt} \% \mathrm{NaCl}$ ( $\mathrm{PH} 7.0$ ) solution for an interval of 24 hours. Before immersion in the $\mathrm{NaCl}$ solution, each specimen was masked on all the sides except the surface to be tested and it was cleaned with acetone. Moreover, specimens after being taken from $\mathrm{NaCl}$ solution rinsed with distilled water and dried in hot air oven for $30 \mathrm{~min}$ at $70^{\circ} \mathrm{C}$. The specimens before and after the tests were weighed individually using digital balance which is mandatory. The corrosion rate of specimens was determined and expressed by millimeter per year ( $\mathrm{mm}$ /year) using weight loss method as per ASTM: G-31 [2] [26].

Finally, the scanning electron microscopy (SEM) and energy dispersive spectroscopy (EDAX) were utilized to examine topography and elemental composition respectively after wear and corrosion tests.

\section{Results and Discussion}

\subsection{X-Ray Diffraction (XRD) Analysis}

Figure 2 shows four peaks of the XRD patterns occurred on surface of the 


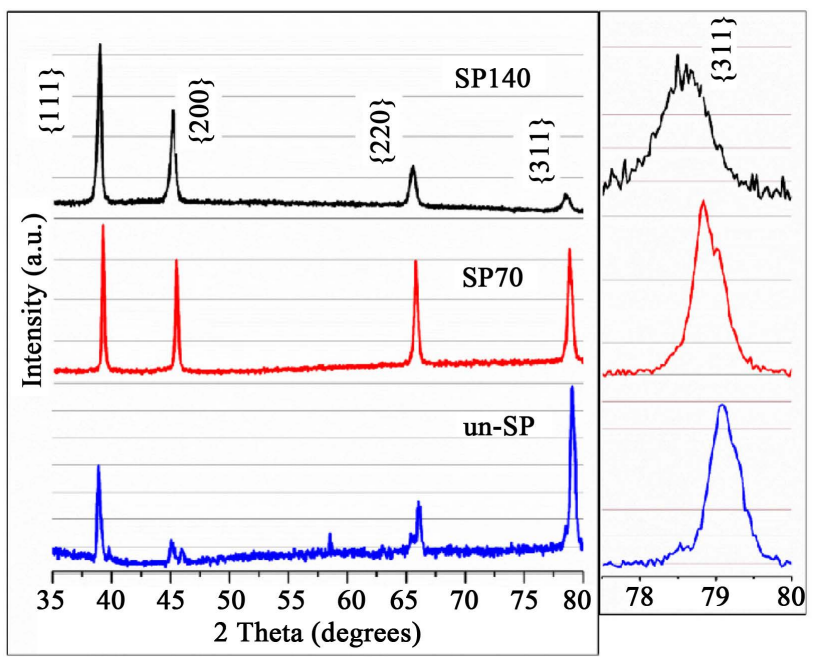

Figure 2. XRD patterns of un-SP, SP70 and SP140 specimens.

specimens. Moreover, the magnified view at $2 \theta=79^{\circ}$ with peak $\operatorname{Al}\{311\}$ is very discernible for the broadening of diffraction peaks by SP treatment. The SP for $140 \mathrm{~s}$ time is more tenacious and it demonstrates that the broadening of peak increases as increasing the exposure time. Moreover, the peak broadening is an indication to the grain refinement [19] and it contributes to develop NC structure and increased dislocation density. Besides, the shifting of peak towards lower side of diffraction angle is also observed from magnified view. It is a sign to understand that the SP can increase the atomic level lattice strain which helps in improving several surface characteristics [13]. The surface characteristics such as FWHM, average grain size, dislocation density and lattice parameter were calculated according to referenced article [13] using X pert high score software and are shown in Table 2.

\subsection{Microhardness}

The improvement in hardness of peened specimens is mainly attributed to the presence of refined grains and high value dislocation densities [27] [28]. The microhardness of un-SP composite is only 89 VHN seen from Figure 3(a), which is similar to the stir casted AA6061composite with $10 \mathrm{Vol} \%$ fraction of $\mathrm{SiC}$ particles [5]. Hence, SP is considered to be an important work-hardening process and induces high hardness as a consequence of grain refinement and high dislocation densities on the metallic surfaces [27] [29]. Moreover, the improvement in work hardened layer in this study correlated with FWHM values of Table 2 as they are having direct proportionality to each other [30].

On the other hand, the trend of hardness profile on the cross-section of the specimens shown in Figure 3(b) helps to assess the thickness of the plastically deformed layer. Therefore, the shot peened specimens have hardened layer up to 40 - $50 \mu \mathrm{m}$ depth. But SP140 specimen had shown substantial improvement beyond the $50 \mu \mathrm{m}$ depth. This is attributed to the improvement in grain refinement, high dislocation density and FWHM broadening after $140 \mathrm{~s}$ SP duration. 


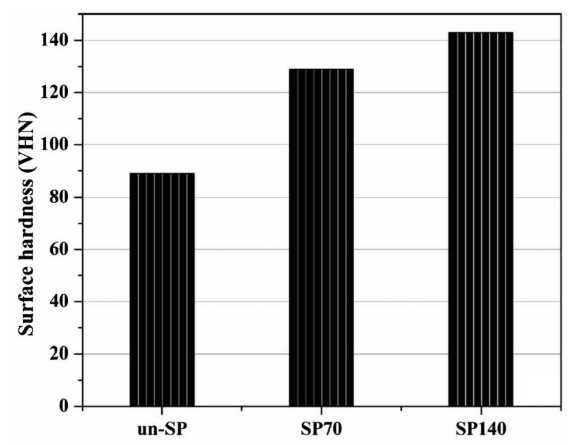

(a)

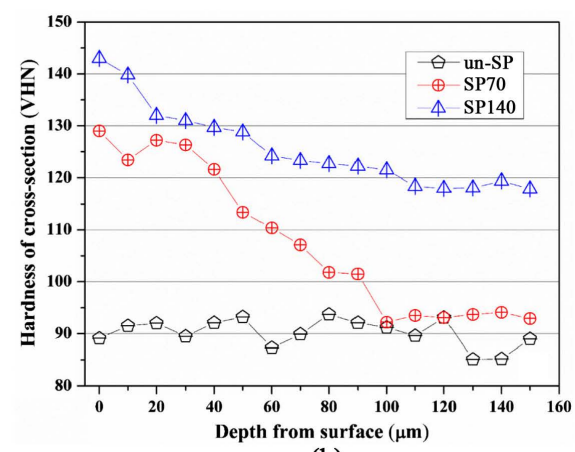

(b)

Figure 3. Microhardness on (a) Surface; (b) Cross-section.

Table 2. Surface characteristics of the specimens by XRD.

\begin{tabular}{ccccc}
\hline Condition & FWHM $\left(^{\circ}\right)$ & $\begin{array}{c}\text { Grain size } \\
(\mathrm{nm})\end{array}$ & $\begin{array}{c}\text { Dislocation density } \\
\left(\times 10^{14} / \mathrm{m}^{2}\right)\end{array}$ & $\begin{array}{c}\text { Lattice } \\
\text { parameter }\end{array}$ \\
\hline un-SP & 0.18 & 55.4 & 8.1 & 4.007 \\
SP70 & 0.24 & 38.8 & 13.4 & 3.972 \\
SP140 & 0.29 & 33.7 & 19.2 & 3.949 \\
\hline
\end{tabular}

\subsection{Wear Behavior}

Based on the above microhardness study the wear behavior of composite before and after SP had studied by testing on pin-on-disc apparatus. In this regard, the trend of coefficient of friction (COF) curves and their average values over the sliding distance of $500 \mathrm{~m}$ are shown in Figure 4(a) and Figure 4(b). It is noted that the specimens after SP have possessed low COF values. It is due to work-hardening layer induced in the near surface of specimens after SP and their improved surface characteristics. SP140 specimen has the lowest COF as compared with other specimens. The enhancement in the surface integrity and microstructure by SP contributed to yield low COF value [31]. Besides, Figure 4 (c) is more discernible that the treated composites are having the lowest wear rate which is attributed essentially to the NC structure and dislocation density improved by virtue of SP.

On the other hand, Figure 5 demonstrates the topography of worn surfaces under a constant load of $15 \mathrm{~N}$. The un-SP specimen had transferred more material during wear test and the nature of wear is adhesive with deep groves and ploughing as seen from Figure 5(a). Because of the coarse grains and low hardness on the surface of specimen without SP could not prevent the material loss form the surface. Whereas, SP70 specimen had shown minimum material loss with mixed adhesive and mild abrasive wear (Figure $5(b)$ ) as a result of improved surface properties and microhardness by SP. In addition, as extension of SP duration the SP140 specimen has received more ability to mitigate loss of material from its surface during wear test. And also Figure 5(c) confirmed the transformation of wear mechanism into abrasive nature by virtue of its high surface hardness and dislocation density as a consequence of $140 \mathrm{~s}$ SP duration. 


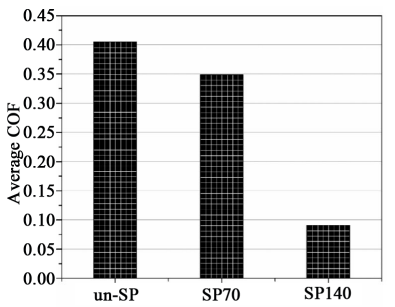

(a)

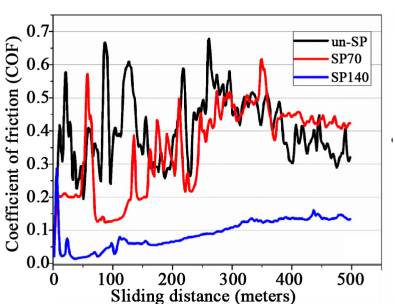

(b)

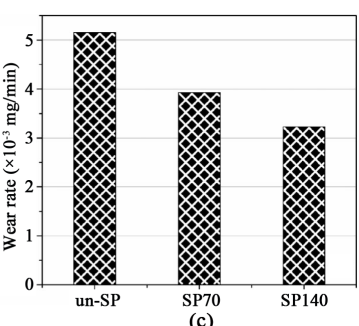

(c)

Figure 4. (a) Average COF; (b) COF trend over sliding distance; (c) Wear rate.
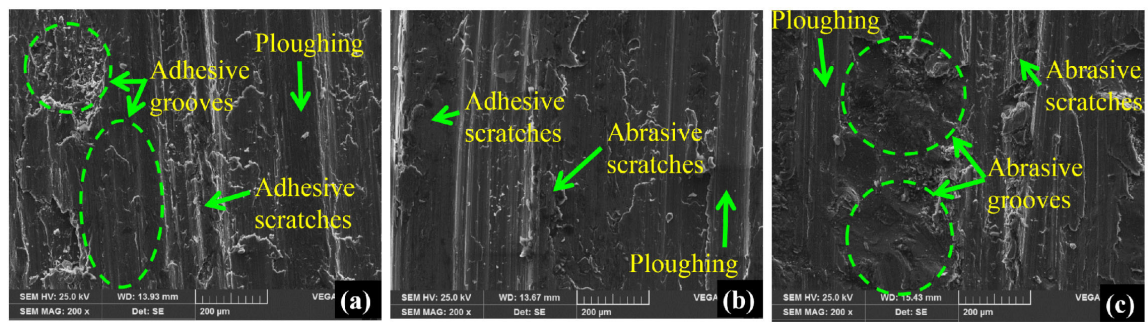

Figure 5. Surface topography of worn surfaces (a) un-SP; (b) SP70; (c) SP140.

\subsection{Corrosion Behavior}

The corrosion behavior of all the specimens is evaluated after exposed for 24 hours in $3.5 \mathrm{wt} \% \mathrm{NaCl}$ solution and the corrosion rate of the specimens is presented in Figure 6. The shot peened specimens showed lower corrosion rate and higher corrosion resistance compared to the untreated specimen. Since NC structure developed by SP acts as barrier layer to corrosion and disrupts the ion release. The surface characteristics resulted after $70 \mathrm{~s}$ SP duration have provoked to improve corrosion properties and shown favor to increase the highest corrosion resistance in this study. The combined surface characteristics such as NC structure and dislocation density in SP70 had governed the corrosion behavior of the composite to yield the best results.

Whereas, the corrosion rate of SP140 specimen is higher when compared to SP70. In general, the corrosion resistance increases with SP exposure time [32]. But increasing SP time for $140 \mathrm{~s}$ in this study had shown lower corrosion resistance compared to $70 \mathrm{~s}$ SP time. Since, increasing dislocation density after longer SP duration is considered to be detrimental effect on corrosion resistance [13]. Therefore, the dislocation density attained by $140 \mathrm{~s}$ SP duration may be more dominant than NC structure obtained. Finally, SP140 specimen has exhibited lower corrosion resistance compared to SP70 specimen due to the differences in their dislocation densities.

On the other hand, the results of SEM analysis after corrosion tests in 3.5\% $\mathrm{NaCl}$ solution are presented in Figures 7(a)-(c). The corroded surface before SP is combined with more cracks and pits. The coarse grains over the surface of the specimen without SP caused severe attack by the corrosion. Whereas, the surface of composites after SP for 70 and $140 \mathrm{~s}$ duration consists of the type intergranular corrosion. But, the corroded surface of SP140 is more degraded compared to 


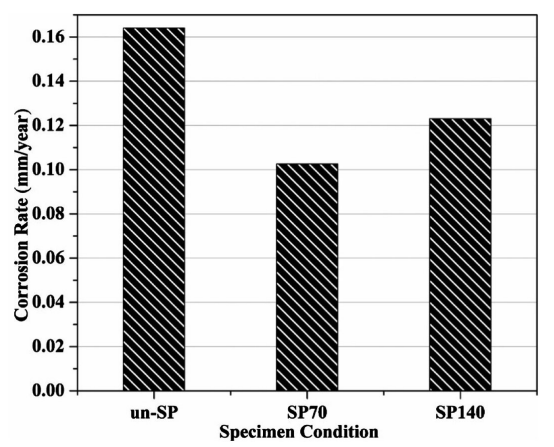

Figure 6. Corrosion rate after static immersion in $\mathrm{NaCl}$.
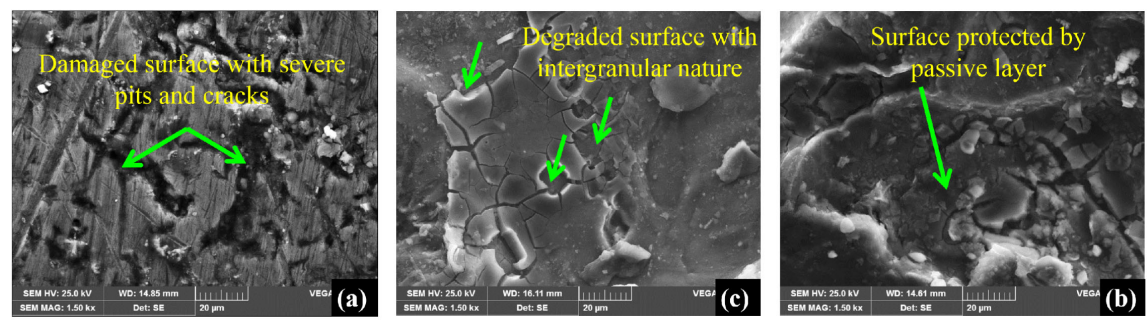

Figure 7. Surface topography of corroded surfaces (a) un-SP; (b) SP70; (c) SP140.

the SP70 specimen as a result of high dislocation density caused by the longer SP duration.

\subsection{Elemental Study on Worn and Corroded Surfaces}

The increase in $\mathrm{O}_{2}$ percent detected on the worn surfaces of EDAX study is an indication to prevent the material transfer and increment in wear resistance. The presence more $\mathrm{O}_{2}$ element observed on the surfaces of shot peened composites as seen in Figure 8(a). It helps to form oxide layer over the surface and strives to prevent material loss from the surface. Since, oxide layer formed on the surface of $\mathrm{Al}-\mathrm{SiC}$ composite during the dry sliding wear tests is an indication to the protection of material loss [33]. But in the case of untreated composite seen in Figure 8(a) have consisted of only a low percent of $\mathrm{O}_{2}$, which could not prevent the loss of material and also shown highest wear rate.

Moreover, the result of EDAX test in Figure 8(b) reveals the presence of $\mathrm{O}_{2}$ in corroded surfaces too. The coarse grained surface of un-SP specimen disrupted the formation of passive layer and increased the corrosion rate due to oxygen deficiency. Because corrosion always occurs in the surface region of oxygen deficiency [34]. The NC structure developed by SP contributes to form thick passive layer [35] with presence of high oxygen content and improved corrosion resistance in SP70 and SP140 specimens. However, the NC structure of SP140 specimen had low oxygen content compared to SP70 due to the difference in dislocation density.

Therefore, the brake rotor disc (BRD) of an automobile manufactured with

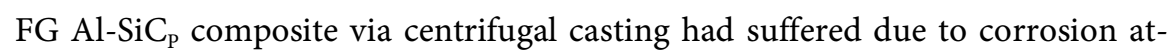
tack even it had high wear resistance. The presence of high $\mathrm{SiC}_{\mathrm{p}}$ in the composite 


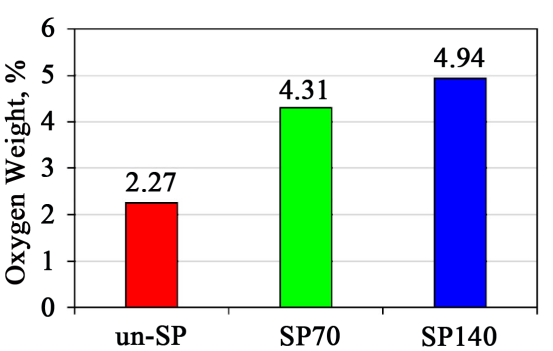

(a)

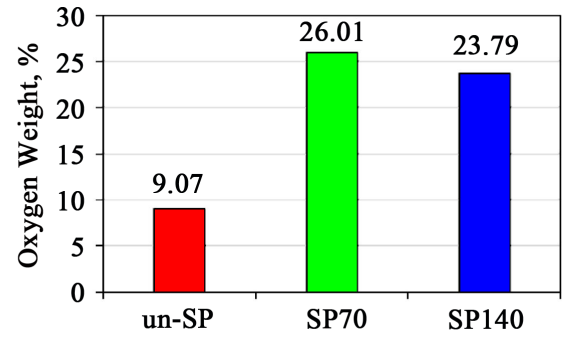

(b)

Figure 8. Elemental report on surfaces after (a) Wear test; (b) Corrosion test.

is more sensitive to the corrosion and it is increased by increasing $\mathrm{SiC}_{\mathrm{p}}$ fraction at the outer surface after centrifugal casting. However, by conducting heat treatments, only few had improved corrosion resistance but some of the heat treatments were not. In order to bypass these difficulties the NC structured surface developed by SPD is the best alternative which increases both wear and corrosion resistance. Thus, a $\mathrm{FG} \mathrm{Al}-\mathrm{SiC}_{\mathrm{P}}\left(10 \mathrm{wt} \% \mathrm{SiC}_{\mathrm{P}}\right.$ ) composite in this study was subjected to SP as one of the SPD treatment and continued for 70 and $140 \mathrm{~s} \mathrm{du}-$ ration. Indeed, SP is more advantageous than few heat treatments by its low cost, flexible, time saving and promising technique to develop NC structure. After SP, the surface characteristics studied by XRD. Thereafter the surface characteristics

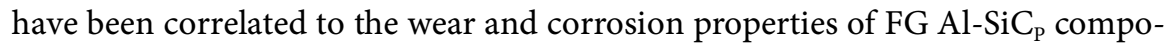
site.

\section{Conclusions}

Finally, the wear and corrosion behavior of the $\mathrm{FG} \mathrm{Al}-\mathrm{SiC}_{\mathrm{P}}$ composite before and after SP was studied with respect to the surface characteristics and the following conclusions can be drawn.

1) The NC structured layer on the surface of shot peened composites is developed successfully. The longer duration of SP promoted the composite surface in terms of highly refined grains, high dislocation density and peak broadening with shifting towards lower diffraction angle.

2) In the top surface NC structured layer, the composite microhardness is improved. It is a consequence of grain refinement and dislocation density increased by SP. And the hardened layer below the surface is increased as the result of longer SP duration.

3) The SP140 exhibited high wear resistance and low friction coefficient due to its grain refinement, high dislocation density and increased microhardness by longer SP duration. But, high dislocation density disrupted the passive layer formation and weakened the corrosion resistance with degraded surface after corrosion test.

4) Whereas, the SP70 with attained degree of NC structure and low dislocation density compared to SP140 composite have increased the corrosion resistance, and also exhibited a relatively good wear properties compared to un-SP composite by its improved surface characteristics after SP. 
5) Thus, the wear resistance of the composite improved greatly with NC structure, high dislocation density and longer SP duration. Besides, the corrosion resistance of the composite governed by a combination of suitable SP duration, NC structure and low dislocation density.

6) Effect of SP is more pronounced while considering surface properties and mechanical properties among the treated composites as compared to un-SP composite even it is having same $\mathrm{SiC}_{\mathrm{P}}$ fraction. Moreover, compared to other surface modification techniques, SP is low cost, flexible for component of any geometry, time saving and promising technology for improving mechanical properties and surface characteristics.

\section{Conflicts of Interest}

The authors declare no conflicts of interest regarding the publication of this paper.

\section{References}

[1] Sharma, V.K., Singh, R.C. and Chaudhary, R. (2018) Effect of Fly Ash Particles with Aluminum Melt on the Wear of Aluminum Metal Matrix Composites. Engineering Science and Technology, an International Journal, 20, 1318-1323. https://doi.org/10.1016/j.jestch.2017.08.004

[2] Zakaria, H.M. (2014) Microstructural and Corrosion Behavior of Al/SiC Metal Matrix Composites. Ain Shams Engineering Journal, 5, 831-838. https://doi.org/10.1016/j.asej.2014.03.003

[3] Zhu, K., Jiang, C. and Ji, V. (2017) Surface Layer Characteristics of CNT/Al-Mg-Si Alloy Composite Treated by Stress Peening. Surface and Coating Technology, 317, 10-16. https://doi.org/10.1016/j.surfcoat.2017.03.039

[4] Velhinho, A., Botas, J.D., Ariza, E., Gomes, J.R. and Rocha, L.A. (2004) Tribocorrosion Studies in Centrifugally Cast Al-Matrix $\mathrm{SiC}_{\mathrm{P}}$-Reinforced Functionally Graded Composites. Material Science Forum, 456, 871-875. https://doi.org/10.4028/www.scientific.net/MSF.455-456.871

[5] Moses, J.J., Dinaharan, I. and Sekhar, S.J. (2014) Characterization of Silicon Particulate Reinforced AA6061 Aluminum Alloy Composites Produced via Stir Casting. Procedia Materials Science, 5, 106-112. https://doi.org/10.1016/j.mspro.2014.07.247

[6] Bhaskar, K.V., Sundarrajan, S., Rao, B.S. and Ravindra, K. (2018) Effect of Reinforcement and Wear Parameters on Dry Sliding Wear of Aluminum Composites-A Review. Materials Today Proceedings, 5, 5891-5900. https://doi.org/10.1016/j.matpr.2017.12.188

[7] Maimunnisa, S., Gore, P., Rajan, T.P.D. and Raja, V.S. (2018) Role of Centrifugal Casting on Electrochemical Corrosion Behavior of A356- $\mathrm{SiC}_{\mathrm{P}}$ Composite in $3.5 \mathrm{wt} \%$ $\mathrm{NaCl}$. Journal of Materials Engineering and Performance, 27, 4210-4224. https://doi.org/10.1007/s11665-018-3508-2

[8] Trzaskoma, P.P. (1990) Pit Morphology of Aluminum Alloy and Silicon Carbide/Aluminum Alloy Metal Matrix Composites. Corrosion, 46, 402-409. https://doi.org/10.5006/1.3585124

[9] Blau, P.J., Truhan, J.J. and Kenik E.A. (2007) Effects of the Exposure to Corrosive Salts on the Frictional Behavior of Gray Cast Iron and a Titanium Based Metal Matrix Composite. Tribology International, 40, 1335-1343. 
https://doi.org/10.1016/j.triboint.2007.02.020

[10] Vieira, A.C., Rocha, L.A. and Mischler, S. (2011) Influence of SiC Reinforcement Particles on the Tribocorrosion Behavior of Al-SiC ${ }_{\mathrm{P}}$ FGMs in $0.05 \mathrm{M} \mathrm{NaCl}$ Solution. Journal of Physics D, Applications Physics, 44, 185-301. https://doi.org/10.1088/0022-3727/44/18/185301

[11] Bai, M. and Xue, Q. (1997) Investigation of Wear Mechanism of SiC Particulate-Reinforced Al-20Si-3Cu-1Mg Aluminum Matrix Composites under Dry Sliding and Water Lubrication. Tribology International, 30, 261-269. https://doi.org/10.1016/S0301-679X(96)00047-3

[12] Takagi, M., Ohta, H., Imura, T., Kawamura, Y. and Inoue, A. (2001) Wear Properties of Nanocrystalline Aluminum Alloys and Their Composites. Scripta Materialia, 44, 2145-2148. https://doi.org/10.1016/S1359-6462(01)00766-7

[13] Pandey, V., Singh, J., Chattopadhyay, K., Srinivas, N.S. and Singh, V. (2017) Influence of Ultrasonic Shot Peening on Corrosion Behavior of 7075 Aluminum Alloy. Journal of Alloys and Compounds, 723, 826-840. https://doi.org/10.1016/j.jallcom.2017.06.310

[14] Valiev, R.Z., Islamgaliev, R.K. and Alexandrov, I.V. (2000) Bulk Nanostructured Material from Severe Plastic Deformation. Progress in Material Science, 45, 103-189. https://doi.org/10.1016/S0079-6425(99)00007-9

[15] Bagheri, S. and Guagliano, M. (2009) Review of Shot Peening Processes to Obtain Nanocrystalline Surfaces in Metal Alloys. Surface Engineering, 25, 3-14. https://doi.org/10.1179/026708408X334087

[16] Ganesh, B.K.C., Ramanaiah, N. and Rao, N.C. (2012) Dry Sliding Wear Behavior of Ti-6Al-4V Implant Alloy Subjected to Various Surface Treatments. Transactions of Indian Institute of Metals, 65, 425-434. https://doi.org/10.1007/s12666-012-0147-4

[17] Chen, B., Huang, B., Liu, H., Li, X. and Ni, M. (2014) Surface Nanocrystalization Induced by Shot Peening and Its Effect on Corrosion Resistance of 6061 Aluminum Alloy. Journal of Materials Research, 29, 3002-3010. https://doi.org/10.1557/jmr.2014.323

[18] Gan, J., Sun, D., Wang, Z., Luo, P. and Wu, W. (2016) The Effect of Shot Peening on Fatigue Life of Q345D T-Welded Joint. Journal of Constructional Steel Research, 126, 74-82. https://doi.org/10.1016/j.jcsr.2016.07.010

[19] Huang, J., Wang, Z., Bian, K. and Jiang, C. (2012) Thermal Relaxation of Residual Stresses in Shot Peened Surface Layer of $\mathrm{SiC}_{\mathrm{W}} / \mathrm{Al}$ Composite. Journal of Materials Engineering and Performance, 21, 915-919. https://doi.org/10.1007/s11665-011-9982-4

[20] Huang, J., Wang, Z., Bian, K. and Jiang, C. (2012) Investigation for Different Peening Techniques on Residual Stress Field of $\mathrm{SiC}_{\mathrm{W}} / \mathrm{Al}$ Composite. Journal of Materials Engineering and Performance, 22, 782-786. https://doi.org/10.1007/s11665-012-0303-3

[21] Perez, O.R., Garcia-Hinojoosa, J.A., Gomez, F.R., Mejia-Sintillo, S., Salinas-Bravo, V.M., Lopes-Sensenez, R., Gonzalez-Rodriguez, J.G. and Garcia-Perez, C.A. (2019) Corrosion Behavior of A356/SiC Alloy Matrix Composites in 3.5\% NaCl Solution. International Journal of Electrochemical Science, 14, 7426-7436.

[22] Vikas, R.S., Maiya, M.U., Jayakumar, E., Rajan, T.P.D. and Nagaraja, P.B.C. (2014) Processing and Characterization of $\mathrm{SiC}_{\mathrm{P}}$ Reinforced Functionally Graded AA6061 Aluminum Metal Matrix Composites. International Journal of Advancements in Mechanical Aeronautical Engineering, 1, 61-65.

[23] SAE Standard AMS-2431/1 (2011) Peening Media (ASR), Cast Steel Shot, Regular 
Hardness (45 to 52 HRC). SAE International, Pennsylvania.

[24] Laine, S.J., Knowles, K.M., Doorbar, P.J., Cutts, R.D. and Rugg, D. (2017) Microstructural Characterization of Metallic Shot Peened and Laser Shock Peened Ti-6Al-4V. Acta Materialia, 56, 480-486. https://doi.org/10.1016/j.actamat.2016.10.044

[25] Venumurali, J., Reddy, G.B., Kumar, B.P. and Ramakotaiah, M. (2019) Effect of Surface Characteristics on Electrical Resistivity of Shot Peened $\mathrm{SiC}_{\mathrm{P}} / \mathrm{AA} 6061 \mathrm{Com}-$ posite by 4PCPs Method. Materials Today Proceedings, 19, 440-443. https://doi.org/10.1016/j.matpr.2019.07.632

[26] ASTM G31-72 (2004) Standard Practice for Laboratory Immersion Corrosion Testing of Metals.

[27] Luan, W., Jiang, C., Ji, V. and Wang, H. (2009) Effect of Shot Peening on Surface Mechanical Properties of $\mathrm{TiB}_{2} / \mathrm{Al}$ Composite. Journal of Material Science, 44, 2454-2458. https://doi.org/10.1007/s10853-009-3310-5

[28] Xie, L., Jiang, C., Lu, W., Feng, Q. and Wu, X. (2011) Investigation on the Surface Layer Characteristics of Shot Peened Titanium Matrix Composite Utilizing X-Ray Diffraction. Surface Coatings and Technology, 206, 511-516.

https://doi.org/10.1016/j.surfcoat.2011.07.070

[29] Luan, W., Jiang, C., Ji, V., Chen, Y. and Wang, H. (2008) Investigation for Warm Peening of $\mathrm{TiB}_{2} / \mathrm{Al}$ Composite Using X-Ray Diffraction. Materials Science and Engineering A, 497, 374-377. https://doi.org/10.1016/j.msea.2008.07.016

[30] Bagherifard, S., Ghelichi, R. and Guagliano, M. (2010) A Numerical Model of Severe Shot Peening (SSP) to Predict the Generation of a Nanostructured Surface Layer of Material. Surface Coatings and Technology, 204, 4081-4090. https://doi.org/10.1016/j.surfcoat.2010.05.035

[31] Yao, C.F., Dou, X.T., Wu, D., Zhou, Z. and Zhang, J.Y. (2016) Surface Integrity and Fatigue Analysis of Shot Peening for 7055 Aluminum Alloy under Different High-Speed Milling Conditions. Advances in Mechanical Engineering, 8, 1-10. https://doi.org/10.1177/1687814016674628

[32] Slat, W.S., Malau, V. and Iswanto, P.T. (2018) The Effects of Shot Peening on the Corrosion Rate of HQ 805 Machinery Steel. International Journal of Mechanical and Mechatronics Engineering, 18, 95-100.

[33] Pradhan, S., Barman, T.K., Sahoo, P. and Sutradhar, P.G. (2016) Wear Behavior of Al-SiC Metal Matrix Composite under Various Corrosive Environments. IOP Conference Series: Materials Science Engineering, 149, Article ID: 012088. https://doi.org/10.1088/1757-899X/149/1/012088

[34] Avner, S.H. (1974) Introduction to Physical Metallurgy. 2nd Edition, McGraw Hill Publishing, New York.

[35] Krishna, K., Sivaprasad, K. and Narayanan, T. (2012) Localized Corrosion of an U1trafine Grained Al-4Zn-2Mg Produced by Cryorolling. Corrosion, 60, 82-89.

https://doi.org/10.1016/j.corsci.2012.04.009 